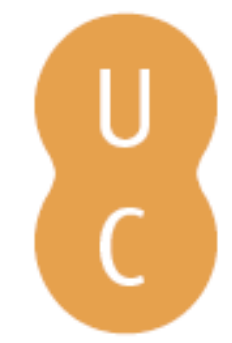

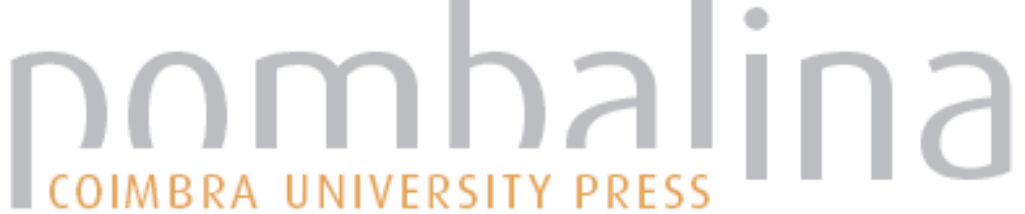

\section{As coleções patrimoniais digitais na cultura do remix: remixing europeana}

\author{
Autor(es): $\quad$ Costa, Ana Rita
}

Publicado por: Imprensa da Universidade de Coimbra

URL

persistente: URI:http://hdl.handle.net/10316.2/41776

DOI: $\quad$ DOl:https://doi.org/10.14195/978-989-26-1362-8_3

Accessed : $\quad$ 26-Apr-2023 08:46:54

A navegação consulta e descarregamento dos títulos inseridos nas Bibliotecas Digitais UC Digitalis, UC Pombalina e UC Impactum, pressupõem a aceitação plena e sem reservas dos Termos e Condições de Uso destas Bibliotecas Digitais, disponíveis em https://digitalis.uc.pt/pt-pt/termos.

Conforme exposto nos referidos Termos e Condições de Uso, o descarregamento de títulos de acesso restrito requer uma licença válida de autorização devendo o utilizador aceder ao(s) documento(s) a partir de um endereço de IP da instituição detentora da supramencionada licença.

Ao utilizador é apenas permitido o descarregamento para uso pessoal, pelo que o emprego do(s) título(s) descarregado(s) para outro fim, designadamente comercial, carece de autorização do respetivo autor ou editor da obra.

Na medida em que todas as obras da UC Digitalis se encontram protegidas pelo Código do Direito de Autor e Direitos Conexos e demais legislação aplicável, toda a cópia, parcial ou total, deste documento, nos casos em que é legalmente admitida, deverá conter ou fazer-se acompanhar por este aviso. 


\section{PESSOAS E IDEIAS EM TRÂNSITO}

Percursos e Imaginários

RITA BASÍLIO DE SIMÕES

CLARA SERRANO

SÉRGIO NETO

JOÃO MIRANDA

(ORGS.)

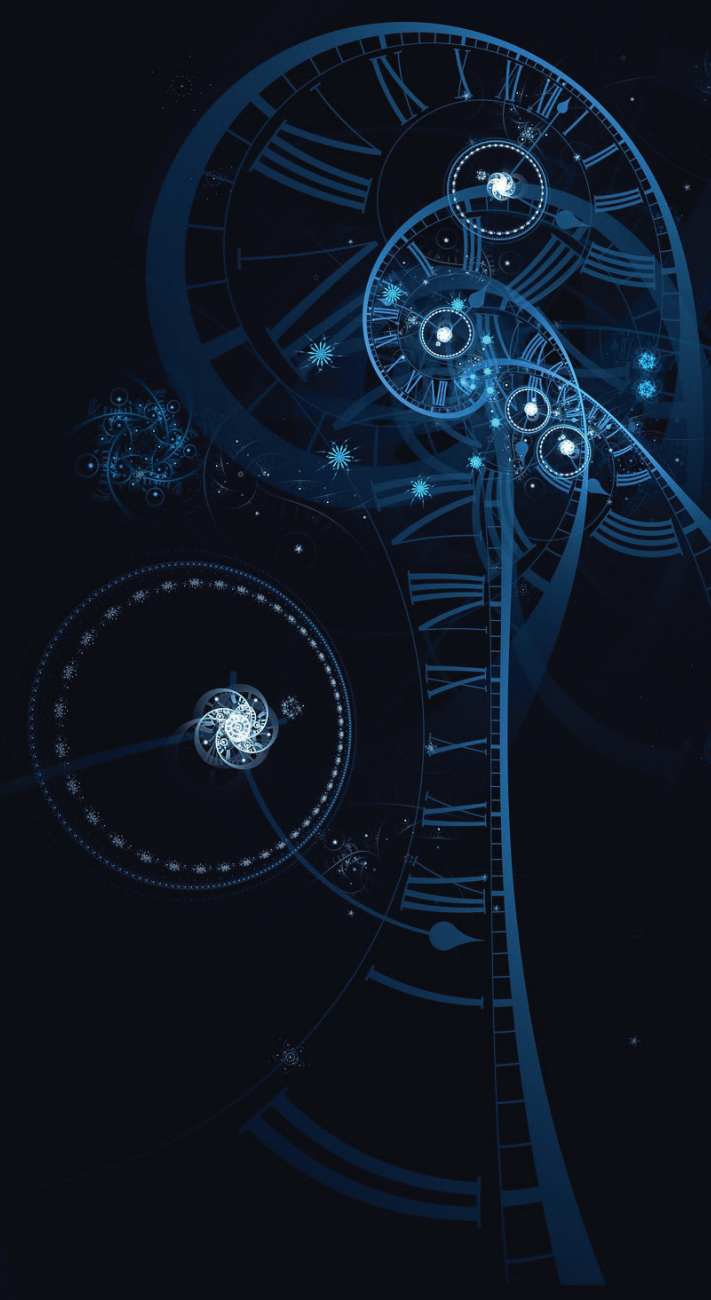

IMPRENSA DA

UNIVERSIDADE

DE COIMBRA

COIMBRA

UNIVERSITY

PRESS 


\section{ASCOLEÇÕ ES PATRIMONIAIS D I G ITAIS}

\section{NA CULTURA DO REMIX:REMIXING EUROPEANA}

Ana Rita Costa

CEIS20

0000-0002-3567-7658

Resumo: Procuramos neste artigo examinar de que modo as coleções patrimoniais digitais se integram na cultura do remix, permitindo e incentivando a reutilização legal e criativa dos materiais disponibilizados. Tendo como objeto de estudo a plataforma a Europeana, concluímos ser um bom exemplo do modo como as coleções patrimoniais digitais podem apoiar uma cultura do remix saudável, ao permitir e incentivar a reutilização criativa dos materiais disponibilizados, não como uma consequência do acesso mas como uma funcionalidade integrada no racional e missão da própria instituição.

Palavras-Chave: Cultura do Remix, Coleções Patrimoniais Digitais, Reutilização de Conteúdos, Direitos de Autor, Europeana

Abstract: In this paper we examine how digital heritage collections partake in the remix culture, allowing and encouraging creative reuse of their contents and facilitating the interaction between cultural institutions and their public. With Europeana platform as study object, we conclude that 
it is a good example of how the digital heritage collections can support a healthy remix culture by allowing and encouraging creative reuse of its contents, not as a result of access but as an integrated feature in rational and mission of the institution, providing new ways of understanding and valuing cultural heritage.

Keywords: Remix Culture, On-line Heritage Collections, Content Reuse, Copyright, Europeana. 


\section{Introdução}

A vulgarização dos computadores pessoais e da Internet provocou uma revolução tecnológica com amplas consequências ao nível da natureza das comunicações e relações sociais, bem como da criação e disseminação de conteúdos, dando origem a uma sociedade global de conhecimento em rede ou cibercultura, que nos obriga a repensar a forma como comunicamos a cultura e o património (Lévy, 1999: 264). Se nos anos 90 a Internet era sobretudo uma plataforma de publicação de conteúdos profissionais, atualmente tornou-se um espaço de intercomunicação e colaboração, no qual conteúdos de produção não-profissional ganham espaço, assumindo-se o utilizador simultaneamente como consumidor e produtor (Jenkins, 2009; Manovich, 2009). As tecnologias digitais, particularmente a Web 2.0, ao tornarem acessíveis a produção e distribuição de conteúdos, converteram-se em importantes instrumentos de criação de conhecimento e cultura, facilitando a participação do utilizador, a interação entre pessoas e a construção da inteligência coletiva $^{1}$ (Lévy, 1999; Manovich, 2009). A reciclagem e reutilização de conteúdos é uma realidade incontornável. Para investigadores como Manovich (2005) e Lessig (2008) a capacidade de editar e remisturar conteúdos existentes, é hoje a forma principal de criação do conhecimento e cultura, originando uma cultura do remix.

Para as instituições cuja missão é transmitir a memória e cultura dos povos, estas alterações significam um repensar o seu papel no mundo globalizado, no qual a identidade cultural é cada vez mais um fator diferenciador. Para manter a sua relevância e reforçar o seu capital cultural devem aprender a usar em

${ }^{1} \mathrm{O}$ conceito de inteligência coletiva refere-se à inteligência/conhecimento que emerge da colaboração entre indivíduos, tendo por base a ideia que ninguém sabe tudo, porém todos sabem alguma coisa. 
seu benefício este novo espaço de comunicação e de criação de cultura e conhecimento. Nos últimos anos museus e bibliotecas têm apostado na sua presença on-line, particularmente através da criação de coleções digitais, representações digitais do património cultural à sua guarda, para comunicar e valorização dos seus acervos patrimoniais, bem como criar novas conexões com os seus públicos. Procuramos aqui examinar, utilizado a Europeana como objeto de estudo, de que modo as coleções patrimoniais digitais podem apoiar uma cultura do remix saudável, permitindo e incentivando a reutilização legal e criativa dos materiais disponibilizados facilitando, assim, a interação entre instituições culturais e públicos, proporcionando novas formas de valorização e compreensão patrimonial e ativando novos processos criativos.

\section{A cultura do remix e suas implicações legais}

O conceito de cultura do remix começou a ser utilizado no início do séc. XXI por investigadores como Lev Manovich (2005) e Lawrence Lessig (2008) para designar uma cultura que é dominada por utilizadores-produtores acostumados a construir e partilhar as suas próprias narrativas, privilegiando processos de criação de conteúdos que envolvem a transformação ou remistura de criações anteriores $^{2}$. Não se trata aqui de plágio ou pirataria, caracterizados pela simples cópia (embora como abordaremos adiante existam também implicações legais no remix), mas da criação de algo novo, que expressa criatividade e significado pessoal, a partir de elementos de objetos culturais ou informacionais preexistentes, nomeadamente

2 O conceito de cultura de convergência utilizado por Jenkins identifica uma realidade semelhante mas preferimos o conceito de cultura do remix por acentuar a reutilização de conteúdos e a criação amadora. 
nas áreas da música, arte, comunicação, multimédia e aplicações web. Para Manovich e Lessig, o remix é hoje o meio dominante pelo qual selecionamos, consumimos e produzimos informação, conhecimento e cultura, constituindo-se como um novo modelo de comunicação em que o "reception point is just a temporary station on information's path. (...) Information arrives, gets remixed with other information, and then the new package travels to other destinations where the process is repeated" (Manovich, 2005).

A reutilização/reinterpretação como método de criação não é novidade, desenvolvendo-se a maioria das formas culturais por meio do empréstimo, reformulação e resposta a formas e estilos de outras expressões culturais. Manovich (2007) considera mesmo que existe um continuum entre a cultura do remix e o pós-modernismo dos anos 80-90, em especial no que se refere às expressões artísticas com as suas noções de reinterpretação, reinvenção e questionamento da aura e autenticidade do objeto de arte. Este fenómeno assume, contudo, maior significado na Era Digital, na qual a acessibilidade das ferramentas de produção criativa e a Internet revolucionaram os meios de produção e distribuição de conteúdos. O remix é agora alimentado pela "digitalização" e acessibilidade online da cultura e informação, bem como pelo surgimento de novas tecnologias digitais associadas à Web 2.0 que facilitam a reprodução e a reutilização de conteúdos e a mistura de formatos (escrita, imagem, som) (Manovich, 2005). Os exemplos mais comuns de remix são o sampling 3 , o comentário e o tagging ${ }^{4}$, o crowdsourcing 5 e os mash-ups de vídeos,

${ }^{3}$ A expressão sampling deriva de o sampler, um aparelho eletrónico que grava e permite a manipulação de trechos sonoros. Refere-se ao processo de isolar trechos de obras musicais e posteriormente reutilizá-los na criação de uma nova obra musical. O hip-hop e rap usam frequentemente o sampling.

${ }^{4}$ Etiquetas ou palavras-chave descritivas utilizadas para identificar ou categorizar conteúdos.

5 Crowdsourcing refere-se ao processo de criação ou desenvolvimento de serviços, ideias ou conteúdos através da contribuição não remunerada de um grupo de pessoas. 
que pode incluir a recombinação de imagens comerciais ou caseiras, informação e música (ex: Youtube), ou de sítios web, com a agregação de informação disponível em vários sítios web numa única plataforma (ex. blog, e-Research e e-Education) (Manovich, 2007).

Para Lessig (2008) a cultura do remix tem como principais efeitos a democratização da cultura e o estímulo da inovação e criatividade, criando um espaço sem precedentes para a produção e disseminação da cultura amadora, onde novas vozes criativas se podem ouvir e no qual o utilizador é ativo no processo de produção de cultura e conhecimento. Esta é uma visão muito positiva do processo de remixagem, cujo potencial democrático e criativo tem sido questionado por alguns autores.

Bart Cammaerts (2008) discute o potencial democrático e participativo da Web 2.0, particularmente da blogosfera, identificando limitações e constrangimentos, que cremos serem extensíveis a outras esferas de produção de conteúdos associadas à cultura do remix. São eles: 1) o domínio crescente das plataformas participativas de criação de conteúdos por grandes grupos de comunicação, entretenimento e tecnológicos (ex. aquisição do Youtube pela Google) perpetuando o seu domínio sobre o espaço público e apropriando-se potencialmente dos direitos sobre os conteúdos criados pelo utilizador-produtor e das mais-valias da sua criatividade; 2) a crescente monitorização e censura dos conteúdos criados por parte de Estados ou organizações, mesmo em países democráticos, o que limita a liberdade de expressão e criatividade do utilizador-produtor; 3) a apropriação do ciberespaço pelas elites culturais e políticas, que dominam mais facilmente as novas ferramentas digitais de produção e disseminação de conteúdos, reforçando assim a sua hegemonia sobre o coletivo e limitando o potencial democrático da cultura do remix.

Outra crítica comum recai sobre a originalidade e qualidade artística dos conteúdos produzidos pela cultura do remix, apontando 
a sua natureza derivativa e afirmando que copiar-colar, remisturar, e reutilizar não é criar. Reynolds (5/10/2012) designa negativamente de "recriatividade" a criatividade produto da cultura do remix, considerando-a uma rejeição da originalidade e do génio criador do artista, acusando os teóricos da cultura do remix de incentivo à cópia e até ao plágio. Contudo, a perceção de que a obra de arte é a expressão material do pensamento e personalidade do seu criador e por isso totalmente original tem sido muito debatida nas últimas décadas e está hoje ultrapassada, considerando-se que a obra resulta sempre de recombinações de fragmentos da tradição que a tornam inteligível (Rosa, 2009: 49). Se alguns conteúdos são muito derivativos e dificilmente classificáveis como obras criativas, muitos seguem, não obstante, a tradição artística de criação de novo material a partir da reinterpretação de referentes culturais de que os movimentos de arte contemporânea, com as suas técnicas que privilegiam o remake, apropriação e colagem, são bons exemplos. O próprio Lessig neutraliza a crítica feita à qualidade dos conteúdos produzidos pela cultura do remix argumentando que o seu valor, este parece-nos um ponto particularmente importante, não é a qualidade ou quantidade mas o seu contributo para a literacia digital e para a formação de uma mentalidade participativa, inovadora e criativa entre os utilizadores. Tal como a escrita académica e criativa, ensinada através do estudo e reutilização de textos para criar argumentos e expressar ideias, vale mais pelo desenvolvimento cognitivo e a capacidade de argumentação que proporciona do que pela qualidade da escrita, o mesmo acontece com o remix, o mash-up e o sample (Lessig, 2008; 93).

A grande crítica à cultura do remix prende-se, contudo, com a sua "difícil" relação com os Direitos de Autor. De acordo com Manovich (2009), a emergência da produção amadora proporcionada pela cultura do remix veio substituir o consumo cultural de massas do séc. XX pela produção em massa de bens culturais 
pelos utilizadores no início do séc. XXI. Isto é, o paradigma de produção e disseminação de conteúdos surgido da possibilidade de reprodução mecânica e da disseminação comercial em larga escala de conteúdos que ocasionou a profissionalização e comodificação da cultura no séc. XX começa agora a ser substituído pela produção em massa de conteúdo amador que se desenvolve numa lógica totalmente diferente, sendo regulada por relações e motivação sociais, que privilegiam a partilha gratuita, e não por ganhos monetários. Esta mudança de paradigma teve um grande impacto sobre os produtores e distribuidores de conteúdos profissionais que veem na cultura do remix uma ameaça aos seus modelos de negócio, quer pela perda de hegemonia dos conteúdos produzidos profissionalmente num ambiente em que qualquer pessoa pode ser um autor, artista, jornalista, etc., quer principalmente pelo uso não autorizado em produções criativas, sítios web e redes sociais de conteúdos sobre os quais detêm Direitos de Autor (doravante DdA) ${ }^{6}$. Perante a acessibilidade dos conteúdos e a disponibilidade de tecnologias para a sua transformação e disseminação, os utilizadores-produtores limitam-se, muitas vezes, a utilizar os conteúdos sem a devida atribuição de autoria, compensação fi-

\footnotetext{
${ }^{6}$ Os DdA protegem formas originais de expressão literária, científica e artística visando um equilíbrio entre o estímulo à criatividade através de uma adequada proteção dos direitos dos criadores, que incluem direitos de natureza moral e direitos materiais/patrimoniais, e o interesse público, estabelecendo exceções em que a utilização pública da obra sem autorização do autor é lícita. Os DdA incluem direitos de natureza moral, referindo-se ao direito do autor reivindicar a paternidade da obra e assegurar a sua integridade, e direitos de carácter patrimonial que se referem aos direitos exclusivos e privilegiados do autor na exploração económica da obra por tempo limitado (até 70 anos após a morte do autor) e que incluem a reprodução, edição, distribuição e utilização por terceiros. Em Portugal os direitos de autor estão legalmente enquadrados pelo Código do Direito de Autor e dos Direitos Conexos - CDADC de 1985 que tem sido atualizado de modo a incluir as diretivas da União Europeia (DL 63/85, de 14 de Março, e alterado pelas Leis 45/85 de 17 de Setembro, e 114/91 de 3 de Setembro, e DL 332/97 e 334/97 ambos de 27 de Novembro, pela Lei 50/2004 de 24 de Agosto, pela Lei 24/2006 de 30 de Junho e pela Lei 16/2008 de 1 de Abril). Sobre este assunto ver Rosa, 2009, p. 27.
} 
nanceira ou pedido de permissão ao autor/ detentor dos direitos para a visualização, edição ou reprodução da obra, criando uma tensão entre a natureza coletivamente apropriável dos conteúdos e a proteção criada pela lei (Rosa, 2009: 91), expondo a centralidade dos DdA na cultura do remix.

Ante os desafios impostos pela Era Digital, a necessidade de repensar o enquadramento legal dos DdA é uma questão muito atual que tem estado na agenda da maioria dos Estados e organizações ocidentais. Enquanto alguns têm procurado adaptar a lei no sentido do alargamento e reforço da proteção legal dos direitos patrimoniais dos titulares, permitindo um controlo mais rígido da difusão e utilização dos conteúdos em ambiente digital7; outros têm procurado modernizar a lei, que consideram ultrapassada e ineficaz face à cultura participativa e colaborativa vigente, de modo a ajustar as suas políticas às transformações sofridas ao nível das práticas de produção cultural e expectativas do utilizador, permitindo um maior equilíbrio na proteção dos interesses de todos os intervenientes e procurando reduzir as limitações legais à construção de uma verdadeira sociedade em rede, bem como à exploração da inteligência coletiva.

Na União Europeia, os direitos de autor em ambiente digital são regulados, de forma geral, pela Diretiva 2001/29/CE - Harmonização dos direitos de autor na Internet (UE/CE, 15/10/2013) ${ }^{8}$, posteriormente transposta para os direitos nacionais9. De acordo com Gonçalves

7 Rosa (2009: 57) designa esta tendência de Combate Público vs Privado que "consiste em, usando estrategicamente as leis, fazer diminuir sucessivamente o espaço do domínio público das obras e assim levar a cabo um cada vez maior processo de privatização da arte e do conhecimento".

${ }^{8}$ Existem várias diretivas para situações específicas que não cabe nem é possível aqui analisar. A diretiva tem um âmbito semelhante e parece surgir no seguimento do americano Digital Millennium Copyright Act 1998. São ainda adotadas nesta diretiva algumas recomendações da World Intellectual Property Organization.

9 Transposta para o direito português pela Lei n. ${ }^{\circ}$ 50/2004 
(2006: 43), esta diretiva tem um espírito economicista, sobrepondo os direitos patrimoniais aos direitos morais, protegendo os interesses económicos das indústrias de produção e distribuição de conteúdos, visando o potencial de valor económico da difusão online enquanto procura limitar o perigo de perda de lucros. Ao estabelecer um controlo legal quase absoluto do autor/proprietário sobre o acesso às suas obras online, a diretiva tem grande impacto sobre o acesso e utilização das mesmas, uma vez que restringe as exceções de reprodução e comunicação livre, nomeadamente transmissões realizadas por instituições sociais ou culturais, agravando também o controlo da cópia privada, tida como ameaça principal aos modelos de negócio atuais. A diretiva estabelece ainda a proteção jurídica das bases de dados atribuindo direitos sui generis aos promotores como forma de proteção de investimento, proibindo a reprodução e extração de informação em quantidade e qualidade substancial, que tem implicações ao nível da possível codificação de obras em domínio público ${ }^{10}$ e da utilização de dados em bruto essenciais no avanço da investigação científica.

Influenciada pelas condições de desenvolvimento da Sociedade do Conhecimento e pelo seu principal projeto cultural, a Europeana (UE, 2006), a União Europeia parece ter vindo a ajustar a sua posição, embora mantenha uma visão que consideramos economicista, admitindo que a política dos DdA deve procurar responder aos desafios da economia do conhecimento assente na Internet, conciliando os diferentes interesses em jogo (UE/CE, 15/10/2013; 18/12/2012) ${ }^{11}$. Documentos como as Comunicações da Comissão

\footnotetext{
${ }^{10}$ Caso das bases de dados/catálogo de bibliotecas, museus e arquivos.

${ }^{11}$ Em dezembro de 2012 a Comissão Europeia iniciou um processo de revisão e modernização geral das leis de DdA na União Europeia. Pretende-se clarificar os direitos sobre os conteúdos gerados pelos utilizadores; facilitar a concessão de licenças aos pequenos utilizadores de material protegido; facilitar a pesquisa de textos e dados para fins de investigação científica atualmente dependentes de disposições contratuais; e rever as exceções de utilização pública.
} 
Europeia Copyright in the Knowledge Economy de 19/10/2009 (UE/ CE, 15/10/2013) e Open data An engine for innovation, growth and transparent governance de 12/12/2011 (UE/CE, 2011) destacam o valor social e económico da circulação e difusão aberta do conhecimento e cultura, particularmente no que se refere a informações geográficas, estatísticas, académicas, educativas e culturais financiadas por fundos públicos, como elementos-chave para o desenvolvimento, criatividade e competitividade da economia Europeia, defendendo um sistema de DdA que privilegie o interesse público, pela facilitação da difusão e utilização destes materiais. A implementação das recomendações incluídas nestes documentos tem vindo a concretizar-se nomeadamente através do alargamento das condições de acesso e de reutilização gratuita ou a custo de produção de documentos do setor público às instituições culturais, aprovada pela Diretiva 2013/37/EU (UE, 2013). Salvaguardando os DdA das obras literárias e artísticas que se conservam nas instituições culturais europeias (n. ${ }^{\circ}$ ), a Diretiva sublinha o valor potencial da reutilização das coleções patrimoniais digitais e metadados conexos na criação de produtos e serviços em setores como o ensino, turismo e indústrias culturais e criativas (n. ${ }^{\circ}$ 15), limitando o valor dos emolumentos cobrados aos custos de produção (n. $\left.{ }^{\circ} 23\right)$ e estabelecendo um período temporal máximo de privilégio para Parcerias Público-Privadas referentes à digitalização de acervos (n. $\left.{ }^{\circ} 30-31\right)$.

Os grandes defensores da revisão do código dos DdA no sentido do afrouxamento dos direitos patrimoniais que o integram têm sido os ativistas do copyleft ${ }^{12}$ dos quais Lessig é o principal represen-

12 É um trocadilho com a expressão inglesa copyright, usada para designar os direitos de autor. É um movimento que visa recuperar o "verdadeiro sentido" dos direitos de autor, defendendo o direito do criador poder gerir as licenças de utilização, difusão e modificação das suas obras, fugindo às limitações impostas pela aplicação das formulações jurídicas clássicas dos direitos de autor e propriedade intelectual. O GNU e o Creative Commons são exemplo de licenças copyleft. 
tante, argumentando que este teve origem numa Era tecnológica e social radicalmente diferente (séc. XIX), em que o trabalho criativo era tido como fechado, desenvolvido por um génio criador, autor único da obra13, e na qual a produção e distribuição de conteúdos só era possível através do sistema empresarial (Rosa, 2009: 45-49). Consideram-no, por isso, inapropriado para a Era Digital por controlar excessivamente a criatividade amadora e inibir a expressão cultural das gerações contemporâneas que privilegiam a criação aberta, coletiva e derivativa, colocando esta nova realidade em questão o conceito tradicional de autor e de ganho monetário como incentivo único para a criatividade e inovação (Lessig, 2008: XVI). Defendem, por exemplo, a desregulamentação da utilização não comercial de conteúdos, passando a adotar-se um sistema de citação ${ }^{14}$, uma vez que o valor de uso não afeta o valor comercial, e uma maior liberdade dos criadores para gerirem as licenças sobre as suas obras. É no seguimento destas ideias que surge a iniciativa Creative Commons que se tornou a forma preferencial de gestão de DdA na cultura do remix por oferecer aos criadores, tanto profissionais como amadores, diferentes níveis de controlo e de permissão para o licenciamento e distribuição das suas obras, de modo a facilitar o seu acesso, partilha e reutilização. O autor pode escolher entre 6 licenças: CC BY - Atribuição, que permite que outros distribuam, remixem, adaptem e criem a partir da obra, mesmo para fins comerciais, desde que atribuam ao autor o devido crédito pela criação original; CC BY-SA - Atribuição-Partilha nos termos da mesma licença; CC BY-NC - Atribuição-Uso Não-Comercial;

13 A noção romântica de autor como génio criador foi posta em causa por Foucault e Barthes na década de 1960, que declaram a "morte do autor" assumindo a obra como construção social.

${ }^{14}$ Lessig (2008: 93) argumenta que, tal como a escrita académica reutiliza textos para criar argumentos e expressar ideias, o mash-up e o sample remisturam e transformam fragmentos de obras para criar novos conteúdos. 
CC BY-ND - Atribuição-Proibição de realização de Obras Derivadas; CC BY-NC-SA - Atribuição-Uso Não-Comercial-Partilha nos termos da mesma licença; CC BY-NC-ND - Atribuição-Uso Não-Comercial-Proibição de realização de Obras Derivadas (Creative Commons, s.d). As Licenças Creative Commons, reconhecidas internacionalmente, têm a grande vantagem de permitirem ao utilizador usar o conteúdo apenas com a citação de autoria e sem necessidade de solicitar permissão de uso ao autor, uma vez que as condições de autorização de utilização são estabelecidas pela licença.

Apesar da relevância da contribuição de Lessig para o debate associado à problemática dos DdA na cultura do remix, a sua posição não é neutral, colocando-se sempre do lado do utilizador e contra as "grandes empresas". Para Lessig, os governos e as empresas de produção e distribuição de conteúdos devem reconhecer os limites da lei face ao progresso tecnológico e à realidade do comportamento social e cultural das gerações atuais, mas o autor parece esquecer, no entanto, que existe uma igual necessidade de ajuste comportamental por parte do utilizador que deve entender que acesso não é impreterivelmente utilização gratuita e incondicional. Existe uma crença comum entre utilizadores, usada frequentemente para justificar as suas ações e que é suportada por Lessig (2008), de que os autores/artistas estão maioritariamente de acordo com a reutilização não comercial das suas obras e que são as "grandes empresas", que os representam e apropriam das mais-valias do seu trabalho criativo, que se opõem à nova cultura do remix. Em Portugal, esta crença parece ser desmentida pelo apoio da Sociedade Portuguesa de Autores ao Projeto Lei N. ${ }^{\circ}$ 118/ XII que reformula o regime de "cópia privada", procurando criar condições que garantam uma compensação equitativa pela utilização de obras intelectuais, fazendo incidir taxas, em favor dos autores, sobre o preço de venda de equipamentos que permitem o armazenamento de ficheiros eletrónicos, compensando dessa forma os 
autores pelas cópias privadas que qualquer utilizador pode fazer, para uso privado, de um álbum ou de um filme. É necessária, por isso, uma pedagogia da literacia digital entre os utilizadores, que lhes permita compreender melhor os limites e consequências da reutilização de conteúdos disponíveis online.

O grande desafio para a cultura do remix parece estar, portanto, na capacidade das Sociedades conseguirem estabelecer um equilíbrio legal entre a proteção dos interesses dos criadores, as expectativas dos utilizadores e o estímulo à criatividade, que favoreça o seu crescimento saudável.

\section{As coleções patrimoniais digitais no âmbito da cultura do remix}

Os museus têm assistido a uma redefinição das suas funções, enfatizam-se noções de democratização do acesso e inclusão, responsabilidade social e renegociação das relações com os públicos através da sua participação e envolvimento na produção de conteúdos multivocais. O tradicional "templo das artes e conhecimento", orientado para a conservação e estudo da coleção, foi substituído pelo "fórum de debate e construção coletiva de experiências culturais", tornando o museu num mediador da relação entre uma comunidade e o seu património cultural. Hoje as instituições de memória devem, sobretudo, inspirar e envolver as pessoas no processo cultural, focando-se na construção dialética de práticas sociais e experiências culturais, nas quais a transmissão hierárquica de conhecimento deu lugar a uma colaboração e diálogo entre as partes envolvidas num processo interativo de construção do conhecimento inspirado pelas teorias construtivistas (Fisher \& Twiss-Garrity, 2007).

A Web 2.0 assume um papel primordial no cumprimento destas novas funções, facilitando o acesso e reinterpretação do nosso 
património coletivo e permitindo a participação e interação com os públicos, melhorando a sua experiência. A capacidade de criar representações digitais de coleções, que podem ser manipuladas através das ferramentas Web 2.0 de uma forma que não é possível fazer com os originais, modifica a forma como os cidadãos se relacionam com o património, tornando-o mais próximo e tangível, favorecendo o seu significado e valorização. Também no âmbito das instituições de memória o remix, alicerçado nas coleções digitais, se vai tornando no modo privilegiado de construção de conhecimento. O remix facilita a construção de narrativas personalizadas e a exploração dos objetos, dando-lhes vida. Os utilizadores tornam-se ativos no processo de descoberta e construção do conhecimento, contribuindo para o desenvolvimento da sua criatividade, capacidades analíticas e de recontextualização de informações (Fisher \& Twiss-Garrity, 2007; Frost, 2009: 240). Ao utilizar representações digitais de objetos, o utilizador pode ir além da mera visualização, sendo possível a análise aprofundada e a descoberta de novas relações entre objetos, a organização de exposições personalizadas ou a adição de informação ao objeto, seja ela contextual, relacional ou de apreciação pessoal, criando uma nova camada de significado pessoal que pode ser partilhada em comunidade. Fisher e Twiss-Garrity (2007) apresentam o caso exemplar do projeto Franklin Remixed no qual alunos do $3^{\circ}$ ciclo de uma escola de Filadélfia aprofundaram os seus conhecimentos sobre Benjamin Franklin e a formação da república americana através da organização de uma exposição virtual que reutiliza objetos digitais de dois museus. Os alunos escolheram os temas e objetos digitais a incluir na exposição, escrevendo textos de apoio e contextualização das imagens. Várias imagens foram transformadas com um editor de imagens criando posters e tiras de cartoon, demonstrando uma capacidade acrescida de criatividade e de reinterpretação do significado cultural dos materiais. 
As coleções patrimoniais digitais assumem ainda um papel relevante na cultura do remix pela riqueza e qualidade dos conteúdos que disponibilizam. Constituindo-se com um arquivo digital e portanto facilmente reproduzível e reutilizável de conteúdos do património cultural comum, podem potenciar a criatividade, uma vez que a cultura e a criatividade são indissociáveis, sendo a obra cultural uma criação social que resulta da reutilização e reinterpretação de formas culturais preexistentes (UE/CE, 2010). Assim, elas oferecem ao criador e ao utilizador comum a oportunidade de contactar com obras de arte, inspirando-os a criar obras novas ou derivadas. A integração de ferramentas Web 2.0 facilita a criação, oferecendo soluções para a reutilização, reinterpretação e remistura de obras em diferentes formatos (imagens, sons e textos) existentes nas coleções patrimoniais digitais (Fisher \& Twiss-Garrity, 2007; Frost, 2009). Em 2012 o Rijksmuseum disponibilizou no seu sítio web o Rijksstudio (https://www.rijksmuseum.nl/en/rijksstudio, consult. 21/10/2013), o qual permite ao utilizador comum, através do simples registo, aceder a 125 mil imagens do acervo, podendo agrupá-las numa coleção pessoal, reutilizá-las, recortando e isolando detalhes ou fazendo colagens, e partilhar as suas escolhas e criações nas redes sociais ou sítio web pessoal. Devido à associação do museu com várias empresas criativas é ainda possível ao utilizador criar produtos baseados nas obras disponibilizadas.

Um bom exemplo de criação artística inspirada por grandes obras do passado é a serie pictórica criada pelo artista havaiano Cheyne Gallarde, que se juntou à Europeana para promover a reutilização criativa de tesouros culturais da Europa disponíveis em domínio público. Com alguma maquilhagem, adereços e um editor de imagens, Gallarde transforma-se e recria alguns dos mais reconhecíveis retratos da cultura europeia, como é o caso dos autorretratos de Vincent van Gogh e Rembrandt. As imagens, mostradas lado a lado com os originais no sítio web e blog 
Europeana, são " a great example of how practicing artists can not only be inspired by masterpieces, but actually use them in their work" (Europeana Professional, 29/05/2013).

O remix de materiais disponibilizados pelas coleções patrimoniais digitais requer, contudo, alguns cuidados. As instituições de memória têm tido algumas reservas em integrar plenamente os seus conteúdos na cultura do remix permitindo a sua disponibilização e utilização aberta ${ }^{15}$, continuando a considerar que detêm sobre eles direitos de propriedade e que os utilizadores devem pedir permissão para utilizá-los. Embora a grande maioria dos objetos originais e físicos estejam em domínio público, a exceção são geralmente as coleções de arte contemporânea, as instituições de memória continuam, globalmente, a reclamar direitos de autor e conexos sobre as suas representações digitais e as bases de dados que as suportam, pelo que a possibilidade de reutilização dos conteúdos disponibilizados, ainda que para fins não comerciais, não está assegurada16. Os “Termos e Condições” de utilização dos conteúdos disponíveis no sistema MatrizNet ${ }^{17}$, plataforma das coleções digitais dos museus

15 Referimo-nos aqui à disponibilização das coleções patrimoniais digitais como dados abertos. Dados abertos são dados que podem ser livremente usados, reutilizados e redistribuídos por qualquer pessoa - sujeitos, no máximo, à exigência de atribuição da fonte e partilha pelas mesmas regras. Os dados devem estar disponíveis sob custo não superior ao custo razoável de reprodução. A disponibilização de dados abertos é recomendada por exemplo para dados em domínio público ou para informação do setor público, cuja produção resulta da atividade do Estado e foi custeada pelo contribuinte. Na União Europeia a disponibilização de dados abertos é suportada pelas Diretivas 2013/37/UE e 2003/98/CE relativas à reutilização de informações do setor público.

${ }^{16}$ A União Europeia tem, no âmbito da Europeana, recomendado aos Estados Membros que as obras em domínio público mantenham esse estatuto uma vez digitalizadas(UE/CE, 2008: 7). O mesmo parece indicar o n. ${ }^{\circ} 2$ do Art. $^{\circ} 2$ do CDADC, "As sucessivas edições de uma obra, [...] não são obras distintas da obra original, nem o são as reproduções de obra de arte, embora com diversas dimensões."

17 Os mesmos Termos \& Condições são também validos para o MatrizPIX, motor de pesquisa sobre fundos fotográficos digitais em alta resolução, produzidos e geridos pelo ADF/DGPC no âmbito da sua vocação primordial de cedência de imagens dos bens culturais móveis integrados nas coleções dos Museus, Palácios, Monumentos e outros imóveis afetos à DGPC. 
portugueses sob tutela da Direção-Geral de Património Cultural, exemplificam esta situação, esclarecendo que "Os organismos de tutela dos Museus representados no MatrizNet são os detentores respectivos de todos os direitos, incluindo os direitos de autor sobre os dados, imagens, documentação, textos e qualquer outra informação contidos neste sítio" sendo os materiais "disponibilizados para usos não comerciais limitados. Os utilizadores podem fazer a transferência de dados para uso pessoal, sujeitando-se às condições adicionais que possam ser aplicadas a quaisquer materiais deste sítio", devendo sempre "citar o autor e a fonte dos materiais" e ficando os demais usos sujeitos "à obtenção de autorização prévia". (MatrizNet, s.d). Impedida fica a difusão das imagens que parece incluir a sua partilha online com terceiros, visto que a distinção entre uso privado e uso público não é ainda muito clara no que se refere à Web 2.O, podendo a partilha em redes sociais ou blogs ser entendida como uma forma de publicação; bem como a sua reutilização criativa, por se manterem noções de respeito e integridade da obra de arte que inibem a modificação da sua representação digital ${ }^{18}$.

Inquéritos recentemente realizados entre instituições culturais da Europa e EUA (Eschenfelder \& Caswell, 2010; Verwayen et al., 2011) demonstram que esta atitude se prende com as potenciais consequências da disponibilização e utilização aberta de conteúdos, nomeadamente:

- perda de controlo sobre a representação dos conteúdos: o maior receio das instituições é que a disponibilização e utilização aberta de conteúdos possa levar à não atribuição/ identificação errada do objeto ou ao seu uso indesejável, visto que estes deixariam de ser supervisionados pela instituição;

18 Questões discutidas no debate "Serviço Público, Museus e Fotografia" organizado pela Acesso Cultura a 24 outubro de 2013 no Museu da Cidade em Lisboa. 
- perda de autoridade e autoria sobre as descrições dos objetos: tradicionalmente o registo de catalogação do curador é final e imutável e as instituições temem perder o controlo sobre a informação disponível sobre os objetos da sua coleção ao permitir que o utilizador adicione comentários sobre os mesmos; a rejeição da adição de comentários pelos utilizadores prende-se igualmente com preocupações com a qualidade da informação, sentindo as instituições uma necessidade de assegurar que a informação disponibilizada provém de fontes qualificadas e confiáveis;

- perda de reconhecimento social: as instituições culturais enquanto guardiãs da memória coletiva estabelecem fortes conexões com os objetos à sua guarda e seu significado cultural (ex. Louvre - Mona Lisa), existindo o receio que a disponibilização e utilização aberta de conteúdos resulte numa perda de reconhecimento da função social e cultural da instituição, obscurecendo o trabalho desenvolvido;

- perda de rendimento potencial: por um lado as instituições culturais seguem geralmente um modelo de licenciamento e venda das imagens das obras de arte à sua guarda que seria potencialmente ameaçado com a disponibilização e utilização aberta de conteúdos, permitindo injustamente que terceiros lucrassem com conteúdos por elas produzidos e preservados sem uma devida recompensa para a instituição tutelar; por outro lado o financiamento público é em alguns casos dependente da demonstração estatística da utilidade pública da coleção, para a qual os dados de licenciamento de reuso têm um peso significativo.

Não obstante estes receios, que consideramos reais e legítimos, a situação tem vindo lentamente a alterar-se. Nos últimos anos instituições, como o Rijksmuseum, o Getty Museum e a Europeana, 
têm abertos dados relativos a representações digitais de obras em domínio público presentes nas suas coleções. As instituições começam a reconhecer a disponibilização e utilização aberta de conteúdos com parte da sua missão enquanto guardiãs do património cultural comum, ao facilitarem a descoberta e interação com as coleções, sendo simultaneamente uma forma de aumentar a sua visibilidade/relevância cultural entre a geração born digital.

\section{Remixing Europeana}

A Europeana é uma iniciativa da União Europeia, lançada online em 2008 com o objetivo de agregar e disponibilizar online o património cultural e científico à guarda das instituições culturais europeias, como suporte de uma economia baseada no conhecimento e na inovação. Ficando as coleções acessíveis na Internet num único sítio $w e b^{19}$, "os utilizadores podem aceder à Europeana para explorar e combinar material digitalizado de museus, bibliotecas e arquivos, inclusive arquivos audiovisuais, de toda a Europa, sem necessidade de conhecer ou visitar múltiplos sítios. Terão acesso direto a livros, jornais, material de arquivo, fotografias e ficheiros audiovisuais digitalizados, podendo consultá-los ou utilizá-los para atividades de lazer, estudo ou trabalho", destacando-se as áreas da educação, turismo, indústrias criativas e culturais (UE/ CE, 2008; UE, 2006).

A reutilização dos materiais disponibilizados e o entendimento de que esta desempenha um papel importante na valorização do

19 A Europeana reúne as coleções digitais de cerca de 2200 instituições culturais europeias, proporcionando acesso a 25 milhões de objetos culturais digitais. Não "guarda" as coleções das várias instituições fornecedoras de dados mas antes agrega os metadados e uma pré-visualização de cada objeto digital, redirecionando depois o utilizador para o portal da instituição. (EUROPEANA PROFESSIONAL, s.d. a) 
património cultural, facilitando a relação entre cidadãos e a sua cultura, bem como no estímulo da inovação e do crescimento social e económico, estiveram presentes desde a conceção do projeto Europeana, mas foram reforçados pelas linhas estratégicas definidas no Europeana Strategic Plan 2011 - 2015, que coloca a ênfase do desenvolvimento da Europeana:

- no incentivo da inovação, empreendedorismo e criatividade no setor das indústrias culturais e criativas através da partilha aberta e reutilização de conhecimentos e dados, que permita fornecer as ferramentas e infraestrutura para que outros possam construir serviços para o utilizador final;

- na disseminação de conteúdos em plataformas de grande utilização pelo público (redes sociais e colaborativas, plataformas móveis);

- e no desenvolvimento de novas maneiras para as pessoas participarem e se envolverem na construção e valorização da sua herança cultural, promovendo a reutilização criativa e educacional dos conteúdos, e melhorando a experiência do utilizador (Europeana, 2010 a:11-19).

No sentido de concretizar os objetivos estabelecidos pelo plano estratégico, a Europeana tem utilizado as tecnologias Web 2.0 para desenvolver recursos que, por um lado facilitam a interatividade com o utilizador final, e por outro incentivam e facilitam a reutilização criativa dos conteúdos por indústrias culturais e criativas.

\section{Soluções tecnológicas que suportam o remix na Europeana}

A Europeana suporta a reutilização de conteúdos e de metadados, considerando para o efeito que um conteúdo é uma obra, 
física ou digital, enquanto os metadados se referem às informações descritivas e técnicas sobre os conteúdos.

A partir de outubro de 2012 a Europeana passou a disponibilizar os seus metadados em Linked Open Data ${ }^{20}$ (Europeana Professional, s.d. d). Esta iniciativa visa incentivar o empreendedorismo e criatividade na economia digital, proporcionando às indústrias culturais e criativas uma oportunidade para criar aplicativos inovadores, jogos para tablets e smartphones, novos serviços online ou sítios web, através da reutilização de conteúdos culturais em domínio público, melhorando a acessibilidade das coleções e a experiência do utilizador final.

A disponibilização aberta de metadados facilita o Europeana API Service $^{21}$, um serviço que permite construir aplicações móveis, sítios web e mash-ups, a partir da base de dados da Europeana, proporcionando uma exibição personalizada dos conteúdos (Europeana Professional, s.d. c). Apesar de poder ser utilizada pelo utilizador comum, esta ferramenta destina-se sobretudo às indústrias culturais e criativas e às instituições fornecedoras de dados. O Europeana API Service tem sido usado sobretudo para facilitar e melhorar os resultados de pesquisa, permitindo recuperar informação georreferenciada ou relacionada, ou para criar novas experiências interativas para os utilizadores, como a organização de exposições personalizadas. Até Julho de 2013 tinham sido criadas cerca de 30 aplicações utilizando o Europeana API Service que não é possível analisar na totalidade no âmbito deste trabalho (Europeana Professional, s.d. b). Destacam-se a HISPANA (http://hispana.mcu.es, consult. 21/10/2013) e Digital Humanities Observatory (http://discovery.dho.ie/discover.php, consult.

20 É uma forma de publicação de dados abertos estruturados que permite que estes sejam enriquecidos, relacionados e reutilizados através de tecnologias Web 2.0, no intuito de criar valor acrescentado.

${ }^{21}$ API é o acrónimo inglês de Interface de Programação de Aplicações. Trata-se de um conjunto de rotinas, padrões e protocolos que facilita a construção de aplicações de software. 
21/10/2013) que complementam os resultados da pesquisa nas suas plataformas com resultados relacionados da Europeana. A Inventing Europe The Foundation for the History of Technology (http://www. inventingeurope.eu, consult. 21/10/2013) que explora a história da tecnologia na Europa por intermédio de visitas virtuais, baseadas em objetos e imagens, e enriquecidas com materiais relevantes de coleções disponíveis na Europeana. O sítio web oferece atualmente 6 exposições e 34 visitas virtuais, que podem ser escolhidas aleatoriamente pelo utilizador, sendo cada visita uma coleção de 4 a 6 histórias que descrevem um aspeto da história da tecnologia na Europa. Por sua vez, a Europeana Culture Collage (http://www. zenlan.com/collage, consult. 21/10/2013) permite a pesquisa por palavra-chave, sendo a recuperação de informação feita através de imagens que depois podem ser guardadas para criar um scrapbook.

O remix e interação com os conteúdos por parte do utilizador comum é igualmente significativa. Exploramos aqui o sítio web Europeana, o projeto de crowdsoursing Europeana 1914-1918 e Europeana Remix, a página Pinterest da Europeana e a aplicação móvel Europeana Open App. O sítio web Europeana (http://www. europeana.eu, consult. 20/10/2013 ) é a principal plataforma de interação entre conteúdo e utilizador final, permitindo a pesquisa e visualização de toda a base de dados. A pesquisa pode ser feita por palavra-chave, título, criador, tema, data ou lugar e depois refinada por formato digital, língua, país, instituição fornecedora e licença de copyright, permitindo encontrar com alguma facilidade grupos de objetos relacionados dentro da temática de interesse do utilizador. As funcionalidades de reutilização dos conteúdos dependem do tipo de pesquisa. A pesquisa aberta permite apenas imprimir o conteúdo ou partilhá-lo através de email, redes socias e colaborativas ${ }^{22}$. Existe

\footnotetext{
22 Estas opções dependem dos direitos associados aos conteúdos como analisaremos adiante.
} 
uma opção individualizada para fazer citações do conteúdo em artigos da Wikipédia, facilitando a inclusão de conteúdos Europeana naquela plataforma. A pesquisa personalizada, possível após registo, compreende mais algumas funcionalidades de reutilização. $O$ utilizador registado pode, por exemplo, guardar pesquisas e itens para uma visualização e utilização futura. Pode ainda criar tags, adicionando termos em linguagem natural, mais próximos do cidadão comum, aos metadados estruturados e padronizados de acordo com a linguagem técnica, facilitando pesquisas futuras e ajudando a criar novas conexões entre objetos. A opção de guardar itens, juntamente com a possibilidade de lhes juntar um tag, permite criar um arquivo personalizado dos conteúdos favoritos, embora não seja depois possível organizá-los em coleções temáticas. Infelizmente, o sítio web Europeana não permite ao utilizador adicionar comentários sobre os objetos que possam depois ser visualizados na ficha do objeto, criando uma nova camada de interpretação e contextualização aproveitando a inteligência coletiva, o que é tanto mais importante tendo em conta que muitos dos objetos apresentam informação contextual muito básica. Esta opção parece prender-se com a necessidade de manter o valor fundamental da marca Europeana, a confiança e autenticidade, assegurando aos utilizadores que a informação principal provém de fontes confiáveis - bibliotecas, museus e outras instituições culturais acreditadas. Os comentários e interações com o material disponível ficaram assim relegados para o blog e redes sociais, com a vantagem de estarem integrados no workflow dos utilizadores, aumentando a sua visibilidade e chegando a pessoas que normalmente não visitariam o sítio web Europeana. Em Junho de 2012 a Europeana começou a explorar o potencial do Pinterest como plataforma para o envolvimento do utilizador com alguns dos seus conteúdos culturais, livre das restrições do portal institucional, oferecendo uma nova forma de interação com as coleções. A Europeana oferece no Pinterest (http:// www.pinterest.com/europeana, consult. 20/10/2013) 25 álbuns de 
imagens em domínio público e portanto totalmente reutilizáveis, sobre temas de moda, arte, fotografia e viagens. No Pinterest estas imagens podem ser comentadas e partilhadas por utilizadores com interesse nos temas abordados. Os comentários podem ir de uma simples apreciação da beleza do objeto, a informação contextual que enriquece o conhecimento sobre o mesmo. As imagens podem também ser reutilizadas pelos utilizadores em coleções próprias.

A 6 de junho de 2013 foi lançada a primeira aplicação móvel (app) da Europeana (Europeana Professional, 06/06/2013). A Europeana Open Culture proporciona acesso móvel a coleções de algumas das principais instituições culturais Europeias, entre as quais o Museu Nacional de Arqueologia. Todas as imagens incluídas na app estão em domínio público ou têm licença aberta, podendo ser reutilizadas livremente em redes sociais, projetos educacionais ou até comerciais. A aplicação inicia-se com a inserção de uma palavra-chave no campo de busca ou por uma seleção de um dos cinco temas em que se encontram organizadas as coleções: mapas e plantas, tesouros da arte, tesouros do passado, tesouros da natureza e imagens do passado. Ao tocar num thumbnail visualiza-se a imagem na sua resolução completa, podendo o utilizador, ao contrário do que acontece no portal institucional, postar comentários e também ler os comentários de outros utilizadores. Pode ainda conectar outras páginas web (por exemplo, Wikipedia) para obter mais informação sobre o objeto e personalidades com ele relacionadas. Existe também a possibilidade de se adicionar a imagem a uma galeria de favoritos e a consequente criação de um museu pessoal, a partir das imagens selecionadas.

Outro tipo de remix e envolvimento do utilizador final proporcionado pela Europeana é o crowdsoursing. A Europeana1914-1918 (http://www.europeana1914-1918.eu, consult. 20/10/2013) é uma iniciativa de crowdsoursing a qual procura recolher testemunhos, histórias, fotografias, cartas, postais, lembranças e outros itens de pessoas comuns relativos à Primeira Guerra Mundial de modo a 
criar uma nova coleção sobre este período, permitindo ao cidadão comum fazer parte da construção do conhecimento histórico. O sítio web "vive" da contribuição dos utilizadores, que juntamente com uma versão digital do objeto, por exemplo, uma cópia ou fotografia digitalizada, devem fazer upload da história por detrás do objeto através do formulário disponível online. Uma vez submetida, a contribuição é analisada por peritos e depois disponibilizada para pesquisa no sítio web com indicação do contribuidor. Relacionado com a Europeana1914-1918 está a Europeana Remix (http://remix. europeana.eu/, consult. 20/10/2013), uma plataforma interativa baseada no filme "Otto e Bernard" que relata a amizade improvável entre um soldado inglês e um soldado alemão e os esforços das suas famílias para reconstituir as suas histórias, incentivando outros a compartilhar fotografias, cartas e recordações da Primeira Guerra Mundial. O filme combina a tecnologia de ponta (Popcorn.js) com uma variedade de recursos em vários formatos da Europeana, Flickr, Wikipedia, Universidade de Oxford, Google Maps e outros serviços da $w e b$, que são visualizados ao mesmo tempo que decorre o filme, proporcionando várias camadas de informação. Os utilizadores podem deixar comentários e compartilhar as suas histórias, em qualquer ponto do filme sendo estes depois visíveis por utilizadores subsequentes. O Europeana Remix oferece, assim, aos utilizadores uma experiência total de inter-relação de conteúdos culturais.

\section{Enquadramento legal do remix na Europeana}

As bases legais para o acesso, reutilização e redistribuição legal dos conteúdos ${ }^{23}$ e metadados disponíveis na Europeana são esta-

\footnotetext{
23 Trata-se verdadeiramente de pré-visualizações/thumbnails dos conteúdos, pois estes conservam-se sempre nas bases de dados das instituições fornecedoras de dados.
} 
belecidas pelo Acordo de Intercâmbio de Dados Europeana-2012 (DEA), que gere as relações entre a Europeana e as instituições fornecedoras de dados, tornando explícito o que pode e não pode ser feito com os dados, quer pelo utilizador final, quer pela própria Europeana (Europeana, 2012). Na base do DEA estão a Diretiva de reutilização de informações do setor público, com o entendimento de que informação que tenha sido produzida pelo setor público e com fundos públicos deve estar disponível para reuso pelos cidadãos, quer para fins comerciais como não comerciais (UE, 2013), e o Europeana Strategic Plan 2011 - 2015 (Europeana, 2010 a), cujas linhas estratégicas não podem ser concretizadas sem uma maior transparência e liberdade na transferência de dados.

No que diz respeito ao licenciamento dos recursos ingeridos e disponibilizados na Europeana por fornecedores de dados, o DEA estabelece tratamentos diferenciados para metadados e conteúdos. No caso dos metadados, o fornecedor de dados deve renunciar a todos os Direitos de Propriedade Intelectual, podendo a Europeana publicá-los e disponibilizá-los para reuso por terceiros, através do Linked Open Data, sem encargos para qualquer tipo de uso (privado, público, comercial ou não comercial) sob os termos de licença Creative Commons Zero - Domínio Público Universal (CC0) (Europeana, 2012; 9-10). A disponibilização dos metadados em CC0 possibilita a sua reutilização para a criação de novos produtos como por exemplo apps.

O DEA não faz qualquer exigência relativamente aos DdA dos conteúdos disponibilizados através da Europeana, permanecendo estes sob o controlo das instituições que os fornecem, embora a Europeana recomende que as obras do domínio público devem manter esse estatuto, uma vez digitalizadas e disponibilizadas através da Internet (UE/CE, 2008: 7). Os fornecedores de dados têm, no entanto a obrigação de indicar o estado dos DdA de cada um dos conteúdos no campo de metainformação 'edm: direitos', 
disponibilizando a Europeana essa informação em ícones ao lado dos resultados de busca. Isto permite que a Europeana comunique ao utilizador final o que pode fazer com cada um dos conteúdos (Europeana, 2012; 12), podendo este fazer pesquisas filtradas para recuperar apenas os conteúdos reutilizáveis (Europeana, 2012; 15). Tendo em conta a ênfase colocada pela Europeana na reutilização criativa e educativa dos conteúdos, esta informação é de grande relevância. A Europeana disponibiliza quatro tipologias de declarações de DdA para os objetos digitais acessíveis a partir do seu sítio web (Europeana, 2012; 15-18):

- Domínio Público, para os objetos digitais sem direitos de autor e que podem ser livremente reutilizados. Embora a maioria das obras disponibilizadas na Europeana esteja em domínio público, muitas instituições têm estabelecido reivindicações de direitos de autor sobre as representações digitais de obras de domínio público, impedindo a sua reutilização e escolhendo utilizar a declaração Direitos Reservados - Acesso Livre;

- Licença Creative Commons, quando o fornecedor de dados é o detentor dos direitos e quer deixar o objeto digital disponível para reuso por terceiros, sendo apenas necessário referenciar/citar o autor/proprietário. Compreende as 6 licenças com atribuição tradicionais do Creative Commons que pode situar-se entre "todos os direitos reservados" e "nenhum direito reservado", passando pela permissão ou não da criação de obras derivadas e do uso comercial, e a licença Creative Commons de domínio público universal CCO;

- Licença de Direitos Reservados criada pela Europeana, quando o fornecedor de dados é o detentor dos direitos, mas não autoriza a reutilização e limita o acesso. Compreende três declarações padronizadas que indicam as condições 
em que o objeto pode ser visualizado - acesso livre, acesso pago e acesso restrito;

- Obra Órfã de Direito Desconhecido, objeto em que o detentor dos direitos não pode ser identificado e que não pode por isso ser reutilizado.

A Europeana estabelece ainda termos de licença para os conteúdos gerados pelo utilizador, geralmente como parte de projetos de crowdsoursing como a Europeana 1914-1918, Europeana Remix e a Europeana 1989. Estes termos foram desenvolvidos pela Europeana para que o utilizador saiba como a sua "criação" pode ser utilizada e para dar à Europeana o direito usar e publicar esses conteúdos sob uma licença Creative Commons - Partilha nos Termos da Mesma Licença.

Ao dar às pessoas toda a informação necessária sobre a utilização legal dos conteúdos disponíveis no sítio web, ao mesmo tempo que esclarece sob que condições legais fornecem o seu próprio contributo, a Europeana promove uma cultura do remix saudável.

\section{Conclusão}

A cultura do remix veio substituir, no início do séc. XXI, o consumo cultural de massas pela produção em massa de conteúdos culturais pelos utilizadores, levando a uma explosão de participação e criatividade amadora e ocasionando uma mudança de paradigma de produção e disseminação de conteúdos com implicações legais. O remix ou seja, a capacidade de editar e remisturar conteúdos, é hoje o meio dominante pelo qual consumimos e produzimos informação, conhecimento e cultura, não escapando as instituições de memória a esta tendência. As coleções patrimoniais digitais de instituições de memória assumem um papel relevante na cultura do remix pela riqueza e qualidade dos materiais que disponibilizam. 
Ao mesmo tempo facilitam o cumprimento das novas funções institucionais de democratização do acesso e inclusão, responsabilidade social e renegociação das relações com os públicos através da sua participação e envolvimento no processo interativo de construção do conhecimento, melhorando a experiência do cidadão na fruição e valorização do património coletivo. Contudo, as limitações legais à reutilização de conteúdos podem ameaçar a participação e criatividade amadora, sendo o grande desafio para cultura do remix a capacidade de as Sociedades conseguirem estabelecer um equilíbrio legal entre a proteção dos interesses dos titulares de direitos e o estímulo à criação, que favoreça o seu crescimento saudável. Esta tensão faz-se também sentir nas instituições de memória nas quais, se por um lado se recolhessem as potencialidades do acesso e utilização aberta dos materiais das suas coleções patrimoniais digitais, nomeadamente na atração de novos públicos, na democratização e difusão da arte na Era Digital e na criação colaborativa de novos serviços para o utilizador, por outro há uma preocupação com as consequências dessa reutilização sem necessidade de permissão e conhecimento prévio da instituição.

O remix é inerente aos objetivos estabelecidos aquando da criação da Europeana e reforçados pelas linhas estratégicas definidas pelo Europeana Strategic Plan 2011 - 2015 (Europeana, 2010 a), devendo a disponibilização on-line do património cultural e científico europeu suportar o acesso e reutilização dos materiais disponibilizados pelos cidadãos e constituir-se como um arquivo de materiais para o ensino e para as indústrias criativas no desenvolvimento de novos produtos e serviços. Assim, a Europeana utiliza tecnologias Web 2.0 para desenvolver recursos que facilitam a participação e a interatividade, destacando-se a inclusão de ferramentas de partilha e tagging no sítio web principal, os portais para crowdsoursing e a integração em plataformas colaborativas 
e sociais, particularmente o Pinterest através do qual se facilita a criação e partilha de coleções personalizadas. A Europeana incentiva ainda a reutilização de metadados e conteúdos em domínio público da sua base de dados por privados e indústrias culturais e criativas, tendo em vista a criação de serviços inovadores e criativos para o utilizador final. A reutilização dos conteúdos e metadados é facilitada pela declaração, bem explícita no sítio web, dos direitos de autor e conexos inerentes, através de licenças Creative Commons e Direitos Reservados. A Europeana é, portanto, um bom exemplo do modo como as coleções patrimoniais digitais podem apoiar uma cultura do remix saudável, ao permitir e incentivar a reutilização criativa dos materiais disponibilizados, não como uma consequência do acesso mas como uma funcionalidade integrada no racional e missão da própria instituição, proporcionando novas formas de valorização e compreensão patrimonial, ao mesmo tempo que facilita o entendimento dos direitos de autor associados.

\section{Referências bibliográficas}

Cammaerts, B. (2008). Critiques on the participatory potentials of Web 2.0. Communication, culture \& critique, 1 (4), 358-377.

Creative Commons (s.d). Sobre as Licenças. Creative Commons. Disponível em https:// creativecommons.org/licenses/?lang=pt_PT.

Eschenfelder, K. R. \& Caswell, M. (2010). Digital Cultural Collections in an Age of Reuse and Remixes. First Monday, 15 (11).

Europeana (2010 a). Europeana Strategic Plan 2011 - 2015. [The Hague: Europeana Foundation]. Europeana. Disponível em http://pro.europeana.eu/files/Europeana_ Professional/Publications/Strategic\%20Plan\%202011-2015\%20(colour).pdf

Europeana (2012). The Europeana Licensing Framework. [The Hague: Europeana Foundation]. Europeana. Disponível em http://pro.europeana.eu/files/Europeana_ Professional/Publications/Europeana\%20Licensing\% 20Framework.pdf

Europeana Professional (s.d. a). About Us. Europeana Professional. Disponível em http://test-europeana.proteon.nl/about

Europeana Professional (s.d. b). API implementations. Europeana Professional. Disponível em http://test-europeana.proteon.nl/web/guest/api-implementation. 
Europeana Professional (s.d. c). API Services. Consult. Europeana Professional. Disponível em http://test-europeana.proteon.nl/web/guest/api

Europeana Professional (s.d. d). Linked Open Data. Europeana Professional. Disponível em http://test-europeana.proteon.nl/linked-open-data

Europeana Professional (2013, maio 29) Hawaiian artist turns himself into Europe's Masterpieces [Press Release]. Europeana Professional. Disponível em http:// test-europeana.proteon.nl/news/press-releases

Europeana Professional (2013, junho 6) Europeana Releases First Free iPad App[Press Release]. Europeana Professional. Disponível em http://test-europeana.proteon. $\mathrm{nl} /$ news/press-releases

Fisher, M. \& Twiss-Garrity, B. (2007). Remixing Exhibits: Constructing Participatory Narratives With Online Tools To Augment Museum Experiences. In J.Trant \& D. Bearman (Eds), Museums and the Web Conference, San Francisco, 2007. Toronto: Archives \& Museum Informatics.

Frost, O. (2009). When the Object is Digital: properties of digital surrogate objects and implications for learning. In R. Parry (Ed.), Museums in a Digital Age (pp.237-246). London, NY: Routledge.

Gonçalves, M. E. (2006). O direito de autor na era digital na Europa. Revista Sub Judice: Justiça e Sociedade. Internet, Direito e Tribunais, 35, 43-55.

Jenkins, H. (2009) Cultura da convergência. São Paulo: Editora Aleph.

Lessig, L. (2008) Remix: Making Art and Commerce Thrive in the Hybrid Economy. London: Bloomsbury.

Lévy, P. (1999) Cibercultura. São Paulo: Editora 34.

Manovich, L. (2005). Remixing and Remixability. Lev Manovich Official Website. Disponível em http://manovich.net/articles.php

Manovich, L. (2007). What comes after remix?. Lev Manovich Official Website. Disponível em http://manovich.net/articles.php

Manovich, L. (2009). The Practice of Everyday (Media) Life: From Mass Consumption to Mass Cultural Production?. Critical Inquiry, 35 (2), 319-331.

MatrizNet (s.d). Termos e Condições. MatrizNet. Disponível em http://www.matriznet. dgpc.pt/matriznet/TermosCondicoes.aspx

Reynolds, S. (2012, outubro 5). You Are Not a Switch. Recreativity and the modern dismissal of genius. Slate. Consult. Disponível em http://www.slate.com/articles/ arts/books/2012/10/against_recreativity_critics_and_artists_are_obsessed_with_ remix_culture_.html

Rosa, A. M. (2009). Os direitos de autor e os novos média. Coimbra: Angelus Novus.

União Europeia (2006). Recomendação da Comissão de 24 de Agosto de 2006 sobre a digitalização e a acessibilidade em linha de material cultural e a preservação digital (2006/585/CE). Jornal Oficial da União Europeia, L N. ${ }^{\circ} 236$ (31.8.2006). Disponível em http://eur-lex.europa.eu/LexUriServ/LexUriServ.do?uri=OJ:L:200 6:236:0028:0030:PT:PDF

União Europeia (2013). Diretiva 2013/37/UE do Parlamento Europeu e do Conselho de 26 de junho de 2013 que altera a Diretiva 2003/98/CE relativa à reutilização de informações do setor público. Jornal Oficial da União Europeia, L N. ${ }^{\circ} 175$ 
(27.6.2013). Disponível em http://eur-lex.europa.eu/LexUriServ/LexUriServ.do? uri=OJ:L:2013:175:0001:0008:PT:PDF

União Europeia. Comissão Europeia (2008). COM(2008) 513 final. Comunicação da Comissão ao Conselho, ao Parlamento Europeu, ao Comité Económico e Social Europeu e ao Comité das Regiões. O património cultural da Europa ao alcance de um clique Progressos na digitalização e acessibilidade em linha de material cultural e na preservação digital na EU. Bruxelas: Comissão Europeia.. Disponível em http: //eur-lex.europa.eu/LexUriServ/LexUriServ.do?uri=COM:2008:0513:FIN:pt:PDF

União Europeia. Comissão Europeia (2010). COM(2010) 183 final. Livro Verde: Realizar o potencial das indústrias culturais e criativas. Bruxelas: Comissão Europeia. Disponível em http://ec.europa.eu/culture/our-policy-development/ doc/GreenPaper_creative_industries_pt.pdf

União Europeia. Comissão Europeia (2011). COM(2011) 882 final. Communication from the Commission to the European Parliament, the Council, the European Economic and Social Committee and the Committee of the Regions. Open data An engine for innovation, growth and transparent governance. Brussels: European Commission. Disponível em http://eur-lex.europa.eu/LexUriServ/LexUriServ. do?uri=COM:2011:0882:FIN:EN:PDF

União Europeia. Comissão Europeia (2012, dezembro 18). Communication on content in the Digital Single Market. Disponivel em http://ec.europa.eu/internal_ market/copyright/licensing-europe/index_en.htm

União Europeia. Comissão Europeia (15/10/2013). Copyright in the Information society. Disponível em http://ec.europa.eu/internal_market/copyright/copyright-infso/index_en.htm

Verwayen, H., Arnoldus, M. \& Kaufman, P. B. (2011). The Problem of the Yellow Milkmaid: A Business Model Perspective on Open Metadata. Intelligent Television. Disponível em http://pro.europeana.eu/documents/858566/2cbf1f78-e036-4088-af25-94684ff90dc5 